\title{
Role of Doctor in Euthanasia - Teaching Medical Students - Challenges and Perspectives
}

\author{
Padmini HN*, Jagadeesh N
}

Department of Forensic Medicine and Toxicology, VIMS and RC, Bengaluru, India

*Corresponding author: Padmini HN, Department of Forensic Medicine and Toxicology, VIMS and RC, India, Tel: 08025397523; E-mail: padmini.noone@gmail.com

Received date: November 03, 2015; Accepted date: December 15, 2015; Published date: December 20, 2015

Copyright: $(2015$ Padmini HN, et al. This is an open-access article distributed under the terms of the Creative Commons Attribution License, which permits unrestricted use, distribution, and reproduction in any medium, provided the original author and source are credited.

\begin{abstract}
Traditional way of teaching medical ethics is by didactic lectures which covers only the cognitive domain and often the passive transfer of teacher's notes to the student (learner)'s notes without touching the mind of the learner. Role of facilitator in teaching medical ethics that too in Euthanasia requires learning the affective and communicative skills through role plays, video demonstration, debates, problem solving, and case based studies etc. to make the learner understand and practice the various perspectives involved in the role of doctor in Euthanasia. Time constraints in the existing curriculum; trained and committed faculty to venture newer methods of teaching learning are some of the challenges in this regard.
\end{abstract}

Keywords: Euthanasia; Bioethics; End of life care

\section{Introduction}

Currently didactic method is the usual way of teaching medical students. The medical education has shifted from the objective oriented teaching learning to competency based teaching learning. In order to achieve competency in a doctor the knowledge, skill and attitude play a crucial role. Realizing this, several countries worldwide have shifted to competency based medical education. Amongst medical ethics, the concept of 'role of doctor in euthanasia' poses challenges both for teaching and learning.

Presently in India passive euthanasia is legally allowed, that too with the permission of the jurisdictional High Court. Active euthanasia is not permitted in India [1]. The students are taught/ appraised regarding all types of euthanasia and the role of doctor; however the facilitator remains unbiased by taking a neutral stand with regard to advocating euthanasia and clarifies the legal status prevalent in India.

\section{Methodology}

Ethical issues are often left to be learned through role models. If not, some concepts are taught through didactic lectures. Issues like role of doctor in euthanasia are complex which may require more than the interactive lecture methods like participatory role play, threadbare debates amongst learners and facilitators to get into the better understanding of all intricate ethical issues. But the resources (trained and committed faculty; time) pose a challenge.

We have tried several adjuncts to 'lecture' in order to teach undergraduate students for difficult concepts like euthanasia. One prior experience which was published before was with regards to the use of 'role- play' in teaching ethics. The students were divided into two batches and taught by either 'role play' or 'lecture'. After that they were given a test without prior notice. The test was on case based MCQs mainly dealing with situations where patients have to be dealt with by doctors; and in some dealing with the ethical and legal dilemmas in relation to the topics. After that the marks were tabulated and the independent sample t-test was used to compare the results. Students taught by both 'lecture' and 'role play' gave equal results [2]. One of the reasons may be that the test was of the cognitive type. In order to assess the effectiveness of teaching-learning by 'role play' it may be necessary to assess the affective domain by observing the way they deal with patients (methods like DOPS, mini-CEX, multisource feedback) [3]. The effectiveness of the teaching learning method will be better appreciated that way. From their feedback it was evident that the students thoroughly enjoyed the session. Our observation was that the students actively participated and were energetic and enthusiastic. They were emotionally involved and could relate to the issues at hand.

In the department we have tried various teaching learning methods for subsequent batches. We have collected the feedback from studentstwo per batch who were randomly selected with a total of six students (two for only 'lecture', two for 'lecture' and 'role play', two for 'lecture' and 'debate' methods).

Students who were taught by 'lecture; method without other adjuncts were of the opinion- 'We had a general idea about what euthanasia was prior to the class, however the legal aspects and specific guidelines were clear after the lecture.' They admitted that it was a difficult subject to understand in comparison to the other topics of ethics.' They were of the opinion that 'enough time was spent to understand the concept.' They were in favour of euthanasia of the passive nature when life supporting systems may need to be removed.' However 'when the question of patient's decision arises, it is difficult to analyse whether the subject was being killed and framed or it was a conscious decision by the patient.' They were of the opinion that' lecture method was good; however it would have been better if other methods were also used, for example if debate is conducted so that they can also know what others feel.'

Students were taught by 'debate' as an adjunct to 'lecture.' These students were of the opinion that 'we knew what euthanasia was prior to the session. However the case illustrations and statistical analysis helped to give a clear idea after the session.' They found 'both lecture and debate to be useful, however debate alone would not be sufficient since they were able to analyze the issue and think on the basis of the 
Citation: Padmini HN and Jagadeesh N (2015) Role of Doctor in Euthanasia - Teaching Medical Students - Challenges and Perspectives. J Clin

Page 2 of 2

matter taught by lecture.' They were unable to decide and in dilemma to be for or against euthanasia after the debate. Here the main argument in favour of euthanasia was that it is inhuman to force another person to live a life without quality, and it is correct to respect the patient's wish if they do not wish to live.' They felt that the argument against euthanasia was that 'doctor is a healer and not someone who would remove the patient's life.'

\section{Discussion}

When we analysed the previous research studies, some showed increased learning after 'role play' session compared to 'lecture' [4], some showed same efficacy as we previously observed in our study. Ethics has an accepted place in the curriculum, more can be done to ensure that the recommended content is taught and assessed optimally [5]. The Medical Council of India is also bringing in changes to the curriculum, giving importance to attitude and communication ethics. So it may be concluded that combinations of methods are required to teach ethics to students. While 'lecture' may give knowledge and understanding of the do's and don'ts and current scenario, the 'debate' instills the power of reasoning and thinking. 'Role play' gives feeling and understanding of the suffering of the patient and the emotional and attitudinal challenges posed by the doctor. Evaluation of teaching of ethics also is challenging because ethical values are often displayed by a person when facing certain situations; unfortunately this cannot be assessed on a piece of paper and often there is no single correct answer!! Hoping that all earnest efforts in teaching ethics to medical students succeed in making sincere doctors practicing with dignity, values and respect to human life.

\section{Acknowledgement}

The authors would like to thank the students for participating and cooperating with the different study methods.

\section{References}

1. KhyouchiVeino (2015) Situation Ethics.

2. Noone PH, Raj Sharma S, Khan F, Raviraj KG, Shobhana SS (2013) Use of Role play in undergraduate teaching of medical ethics- an experience. J Forensic Leg Med 20: 136-138.

3. Modi JN, Gupta P, Singh T (2015) Competency - based Medical Education, Entrustment and Assessment. Indian Pediatrics 52: 413-420.

4. Hassanzadeh A, Vasili A, Zare Z (2010) Effects of two educational method of lecturing and role playing on knowledge and performance of high school students in first aid at emergency scene. Iran J Nurs Midwifery Res 15: 8-13.

5. Mattick K, Bligh J (2006) Teaching and assessing medical ethics : where are we now? J Med Ethics 32: 181-185. 